\title{
Cytochrome P450 2D6 profiles and their relationship with outcomes of primaquine anti-relapse therapy in Australian Defence Force personnel deployed to Papua New Guinea and East Timor
}

Nanhua Chen ${ }^{1}$, Simone Dowd ${ }^{1}$, Michelle L. Gatton², Alyson Auliff' ${ }^{1}$, Michael D. Edstein ${ }^{1}$ and Qin Cheng ${ }^{1 *}$

\begin{abstract}
Background: Primaquine, an 8-aminoquinoline with anti-hypnozoite activity against Plasmodium vivax, is metabolized by human cytochrome P450 2D6 (CYP2D6) to its active metabolite. Human CYP2D6 activities may influence the metabolism of primaquine and the risk of experiencing Plasmodium relapses following primaquine anti-relapse therapies (PART). In this study, the CYP2D6 profile and its relationship with outcomes of PART in Australian Defence Force (ADF) personnel is retrospectively investigated.

Methods: Genomic DNA was isolated from stored and de-identified serum or blood samples from ADF personnel deployed on peacekeeping duties to Papua New Guinea (PNG) (1999) and East Timor (1999-2000) who received PART before returning to Australia and after experiencing relapses. CYP2D6 allelic type was determined by PCR and Sanger sequencing. CYP2D6 allele frequency, predicted phenotypes and activity scores were compared among personnel who did not experience P. vivax (ADF-NR, $n=48$ ) and those who experience at least one (ADF-R, $n=109$ ) relapse, as well as between those who experienced $1(n=79), 2(n=21)$ and $3-5(n=9)$ relapses within the ADF-R group.

Results: 16 CYP2D6 alleles were observed in 157 ADF personnel. Alleles ${ }^{*} 1, * 4,{ }^{*} 2$ and ${ }^{*} 41$ were major alleles (> 5\%). The CYP2D6 allele frequency profile in the ADF-NR group matched that of a European population. There was an increased proportion of non-functional CYP2D6 alleles in the ADF-R group compared to the European population and ADF-NR group. However, frequencies of predicted CYP2D6 phenotype and activity score were not different between the ADF-R and ADF-NR groups, nor among sub-groups experiencing multiple relapses within the ADF-R group.

Conclusions: CYP2D6 phenotype or activity score based on the allele classification was not a major contributor to P. vivax relapse in this ADF cohort. Other factors such as adherence and/or parasite tolerance to primaquine are likely contributing factors to $P$. vivax relapses in this cohort.
\end{abstract}

Keywords: Plasmodium vivax, Relapses, Primaquine, CYP2D6 allele, CYP2D6 phenotype, CYP2D6 activity score

\footnotetext{
*Correspondence: qin.cheng@defence.gov.au

${ }^{1}$ Australian Defence Force Malaria and Infectious Disease Institute,

Brisbane, QLD, Australia

Full list of author information is available at the end of the article
} 


\section{Background}

Plasmodium vivax infection is a major cause of human malaria in areas outside Africa [1, 2], and presents a major challenge to the global malaria elimination programmes due to several underlying biological characteristics of this parasite species. Compared to Plasmodium falciparum infections, patients with $P$. vivax often have lower parasitaemias leading to a higher proportion of cases below the limit of detection for microscopy and rapid diagnostic tests (RDTs). There is also a higher proportion of asymptomatic and sub-microscopic carriers in communities who contribute to transmission [3]. Plasmodium vivax parasites produce gametocytes before the appearance of clinical symptoms, and throughout the course of infection leading to more effective transmission. Importantly, a single $P$. vivax infection can cause many episodes of relapses days and months after the original infection due to activation of hypnozoites deposited in the liver of the infected host at the time of the original infection. It has been shown that relapses contribute to $\sim 80 \%$ of all P. vivax infections in Papua New Guinea (PNG) [4]. As a result, $P$. vivax is more resilient to malaria control measures and countries have reported increases in proportion of $P$. vivax infections as they progress from malaria control to elimination [5-7].

Plasmodium vivax relapses can be prevented by using drugs that are capable of killing hypnozoites in the liver. Until recently the only licenced drug for this purpose has been primaquine, an 8 aminoquinoline. The World Health Organization (WHO) recommends that $P$. vivax infected patients (except pregnant or breast feeding women, infants and glucose-6-phosphate dehydrogenase (G6PD) deficient individuals) should receive a 14 day course of primaquine radical cure $(0.25-0.5 \mathrm{mg} /$ $\mathrm{kg}$ body weight daily) to prevent relapses [8]. However, wide use of primaquine is associated with several major barriers. Firstly, primaquine can cause haemolysis in people with deficient G6PD activity. Therefore, primaquine use requires quality point of care G6PD tests. Secondly, the recommended primaquine regimen for preventing relapses is daily primaquine for 14 days and as such often suffers from poor adherence [9-12]. Thirdly, while there is no confirmed evidence of primaquine resistance, it has been documented that $P$. vivax strains in areas of Oceania are tolerant to primaquine [13] with higher doses of primaquine required to effectively prevent relapses [14-16]. Finally, recent publications reported that human cytochrome P450 2D6 (CYP2D6) enzyme is essential for the metabolism of primaquine into its active metabolites $[17,18]$, suggesting that reduced primaquine metabolism may be associated with increased risk of $P$. vivax relapses.

The CYP2D6 activity phenotype can be measured by challenging individuals with a probe substrate, and results are categorized as ultrarapid metabolizer (UM), extensive metabolizer (EM), intermediate metabolizer (IM), and poor metabolizer (PM) [19]. CYP2D6 phenotype can also be predicted by determining the allelic type of the CYP2D6 coding gene. The CYP2D6 gene is polymorphic with over 150 allelic variants defined [20] (https://www.pharmvar.org/gene/CYP2D6). These variants are classified as increased function (IF), fully function (FF), reduced function (RF) and non-function (NF) alleles. However, prediction of CYP2D6 phenotypes from CYP2D6 allelic types can be challenging due to the number of allelic variants and the resulting complexity of combinations. An activity score (AS) system was developed, in that an IF, FF, RF and NF allele receives a score of $2,1,0.5$ and 0 , respectively [20]. This helps to simplify the allelic type interpretation.

There is a considerable variation in the frequency of CYP2D6 alleles among different ethnic groups [19, 21, 22], with variations that translates into CYP2D6 phenotypes. For instance, the proportions of CYP2D6 IM and PM phenotypes are estimated to be $10-15 \%$ and $5-10 \%$, respectively, for Caucasians [23, 24]. In Asians, the CYP2D6 PM phenotype is rare, however, the IM phenotype is about $50 \%$ [22].

Several studies have demonstrated an association between CYP2D6 phenotypes and risk of $P$. vivax relapse. A human experimental challenge trial reported that volunteers with PM and IM CYP2D6 phenotypes had an increased risk of suffering from relapses [25]. A traveller experiencing multiple $P$. vivax relapses despite receiving primaquine radical cure at each episode was found to have a CYP2D6 IM phenotype [26]. Field studies conducted in Brazil [27, 28] and Indonesia [29] suggested that the PM and IM phenotypes or AS below 1.5 and 1, respectively, are associated with increased risk of recurrence of vivax malaria. In contrast, a case study failed to identify mutations at four known mutation sites within CYP2D6 in a patient who failed multiple times after receiving $30 \mathrm{mg}$ of primaquine daily for 14 or 28 days, suggesting primaquine resistance [30].

Plasmodium vivax is also a major health problem for military personnel deployed to malaria endemic areas. While prophylaxes regimens offer effective malaria prevention for deployed troops in endemic countries, primaquine anti-relapse therapy (PART) have not been fully effective in preventing relapses. Relapses of $P$. vivax malaria in military personnel after returning home are common. In Australian Defence Force (ADF) personnel deployed to East Timor, over 400 cases of relapsing vivax malaria were documented in returned troops despite receiving PART [15]. A number of relapsing P. vivax infections were also documented in personnel returning from Bougainville, PNG [31]. A subgroup of personnel 
experienced more than one relapses despite receiving PART after the first relapse. The reasons underlying failures of PART in the ADF cohort are not fully understood.

To understand whether CYP2D6 activity was an identifiable factor in this cohort of ADF personnel who failed PART with $P$. vivax relapses after returning to Australia following deployment to East Timor and PNG, the CYP2D6 allelic profile and relationship between CYP2D6 allele and $P$. vivax relapses was retrospectively investigated in the ADF cohort. Predicted CYP2D6 phenotype and activity scores were compared between the ADF personnel who experienced $P$. vivax relapses and those who did not, and within ADF personnel experiencing different number of relapses. It is anticipated that these findings will help to improve the effectiveness of PART and reduce the risk of $P$. vivax relapses in returning troops.

\section{Methods}

\section{Study cohort and samples}

Stored, de-identified serum or blood samples from 157 ADF personnel deployed on peacekeeping duties to Bougainville, PNG in 1999 and East Timor in 1999-2000 were included in this retrospective study. All personnel who were G6PD normal (determined at enlistment and recorded in personal medical records) received unobserved presumptive PART consisting of doxycycline (100 mg daily for 14 days) and primaquine $(7.5 \mathrm{mg} 3$ times daily or $15 \mathrm{mg}$ twice daily for 14 days, without body weight adjustment) commencing before their return to Australia. The sample set was specifically selected based on whether personnel experienced vivax malaria following their return to Australia. A set of serum samples was selected by computer generated randomization from stored samples from personnel who did not experience $P$. vivax (non-relapse, ADF-NR group, $\mathrm{n}=48$ ) after returning to Australia. The second set comprised samples from all ADF personnel who experienced at least one episode of $P$. vivax after returning to Australia and had a serum or blood sample (ADF-R group, $n=109$ ). Within the ADF- $R$ group, 79, 21 and 9 individuals experienced 1, 2 and 3-5 relapses, respectively. PART at each relapse included primaquine $(7.5 \mathrm{mg} 3$ times daily or $15 \mathrm{mg}$ twice daily for 14 days) for radical cure.

Serum samples that were collected in PNG before PART were stored in liquid nitrogen and transferred to the Australian Defence Force Malaria and Infectious Disease Institute (ADFMIDI) where the samples were stored at $-80^{\circ} \mathrm{C}$. Blood samples were collected, transported to ADFMIDI and stored at $-80^{\circ} \mathrm{C}$.

Plasmodium vivax infections were diagnosed by microscopy at the time of malaria onset. A subset of samples from East Timor were confirmed as malaria-positive by PCR and molecular genotyping [32].

\section{DNA isolation and sequencing}

Genomic DNA was isolated from human serum or blood preserved in $6 \mathrm{M}$ guanidine-HCL (1:10) using a QIAamp DNA Mini Kit according to manufacturer's instructions (QIAGEN). Full length CYP2D6 was amplified with nested PCR using PfuUltra II Fusion HS DNA Polymerase (Aligent) (Table 1). PCR product was then treated with ExoSAP-It (Affymetrix). To determine the SNPs that define specific allelic types of CYP2D6 (https://www.pharmvar.org/gene/CYP2D 6), 7 primers (Table 1) were used to carry out Sanger sequencing using Big Dye v3.1 (Applied Biosystems). Deletions and amplifications of the 2D6 gene were detected following published protocols [33].

\section{CYP2D6 allele determination}

Sequence polymorphisms and gene copy number variations were identified allowing two allelic types of CYP2D6 to be determined for each sample. Homogenous and heterogeneous sequences at each polymorphic loci were recorded and their allelic types were defined following the CYP2D6 naming convention outlined by the Pharmacogene Variation (PharmVar) Consortium (https://www.pharmvar.org/gene/CYP2D6).

\section{CYP2D6 phenotype prediction}

Phenotype prediction from CYP2D6 alleles were made following the matrix used in [26]. Briefly, individuals having at least one increased function (IF) allele or one FF allele regardless of the function of the second allele were predicted as UMs and EMs respectively, while those with two NF alleles were predicted as PMs. Individuals having two RF alleles or one RF plus one NF allele were predicted as IMs.

\section{CYP2D6 activity score (AS) determination}

An AS is assigned to each CYP2D6 allele detected following Gaedigk's method [20, 33]: 2 for an IF allele, 1 for a FF allele, 0.5 for a RF allele and 0 for a NF allele. AS for an individual sample was the sum of AS of the two CYP2D6 alleles detected in that sample.

\section{Statistical analyses}

Comparisons of allele frequency were conducted using Chi-square Goodness of Fit test. A generalized linear model with a log link function was used to assess whether phenotype was a significant predictor of relapse. A receiver operating characteristic curve (ROC) analysis was conducted to determine the optimal CYP2D6 AS threshold to separate ADF-R from ADF-NR. Fishers exact test was used to test for an association between AS and ADF group, while Chi-squire 
Table 1 Primers used for PCR and sequencing CYP2D6

\begin{tabular}{|c|c|c|c|c|c|}
\hline Purpose & Primer (position, bp) & SNPs/indels to detect & Primer sequence $\left(5^{\prime}-3^{\prime}\right)$ & PCR condition & Ref \\
\hline \multirow[t]{2}{*}{$\begin{array}{l}\text { Nested PCR } \\
\text { Round } 1\end{array}$} & $\begin{array}{l}\text { 2D6-DPKup } \\
(-352 \text { to }-320)\end{array}$ & Full length & $\begin{array}{l}\text { GTT ATC CCA GAA GGC TTT } \\
\text { GCA GGCTTC A }\end{array}$ & \multirow{2}{*}{$\begin{array}{l}95^{\circ} \mathrm{C} 1 \mathrm{~min} ; 95^{\circ} \mathrm{C} 20 \mathrm{~s} \\
65^{\circ} \mathrm{C} 20 \mathrm{~s}, 72{ }^{\circ} \mathrm{C} 2 \mathrm{~min} \\
30 \mathrm{~s}, 50 \text { cycles }\end{array}$} & \multirow[t]{2}{*}{ [34] } \\
\hline & $\begin{array}{l}\text { 2D6-DPKlow } \\
\text { (4763 to 4743) }\end{array}$ & Full length & $\begin{array}{l}\text { GCC GAC TGA GCC CTG } \\
\text { GGA GGT AGG TA }\end{array}$ & & \\
\hline \multirow[t]{2}{*}{$\begin{array}{l}\text { Nested PCR } \\
\text { Round } 2\end{array}$} & $\begin{array}{l}\text { 2D6gene sense } \\
(-270 \text { to }-239)\end{array}$ & Full length & $\begin{array}{l}\text { GGC GGC CTA CCC TGG } \\
\text { GTA AGG GCCTGG AGC } \\
\text { AGG A }\end{array}$ & \multirow[t]{2}{*}{$\begin{array}{l}95^{\circ} \mathrm{C} 1 \mathrm{~min} ; 95^{\circ} \mathrm{C} 20 \mathrm{~s}, \\
72^{\circ} \mathrm{C} 2 \mathrm{~min} 30 \mathrm{~s}, 40 \\
\text { cycles }\end{array}$} & \multirow[t]{2}{*}{ [35] } \\
\hline & $\begin{array}{l}\text { 2D6gene antisense } \\
\text { (4413 to 4382) }\end{array}$ & Full length & $\begin{array}{l}\text { CTC AGC CTC AAC GTA } \\
\text { CCC CTG TCT CAA ATG } \\
\text { CG }\end{array}$ & & \\
\hline \multirow[t]{7}{*}{ Sanger sequencing } & $\begin{array}{l}\text { 2D6Ex1FH } \\
(-126 \text { to }-103)\end{array}$ & $\begin{array}{c}31 \mathrm{G}>\mathrm{A}, 77 \mathrm{G}>\mathrm{A}, 100 \mathrm{C}>\mathrm{T}, \\
\text { 124G>A, 137_138ins }\end{array}$ & $\begin{array}{l}\text { CAG CTC CCTTTA TAA GGG } \\
\text { AAG GGT }\end{array}$ & \multirow{7}{*}{$\begin{array}{l}96^{\circ} \mathrm{C} 2 \mathrm{~min} ; 96^{\circ} \mathrm{C} 10 \mathrm{~s}, \\
50^{\circ} \mathrm{C} 5 \mathrm{~s}, 60^{\circ} \mathrm{C} 4 \mathrm{~min}, 30 \\
\text { cycles }\end{array}$} & \multirow[t]{7}{*}{ [34] } \\
\hline & $\begin{array}{l}\text { 2D6-SF4 } \\
\text { (695 to } 717)\end{array}$ & $\begin{array}{l}883 G>C, 1023 C>T \\
1039 C>T\end{array}$ & $\begin{array}{l}\text { CCA AAC TGA GTT CCT } \\
\text { CCA TCA CA }\end{array}$ & & \\
\hline & $\begin{array}{l}\text { 2D6-SF6 } \\
\text { (1417 to } 1436)\end{array}$ & $\begin{array}{l}\text { 1584delG, 1659G }>\text { A } \\
\text { 1661G }>C, 1707 \text { delT, } \\
1716 \mathrm{G}>\mathrm{A}, 1758 \mathrm{G}>\mathrm{T}\end{array}$ & $\begin{array}{l}\text { AGA GAC GAG GTG GGG } \\
\text { CAA AG }\end{array}$ & & \\
\hline & $\begin{array}{l}\text { 2D6Ex4F1s } \\
\text { (1780 to } 1797)\end{array}$ & $\begin{array}{l}\text { 1846G }>\text { A, } \\
\text { 1863_1864insTTTCGCCC, } \\
\text { 1973_1974insG, 1978C }>\text { T, } \\
\text { 1979T }>C, 2291 G>A\end{array}$ & $\begin{array}{l}\text { ACA AAG CGG GAA CTG } \\
\text { GGA }\end{array}$ & & \\
\hline & $\begin{array}{l}\text { 2D6Ex5F2s } \\
\text { (2318 to 2339) }\end{array}$ & $\begin{array}{l}\text { 2539_2542delAACT, } \\
\text { 2549delA, } \\
\text { 2573_2574insC, } \\
\text { 2587_2590delGACT, } \\
\text { 2615_2617delAAG }\end{array}$ & $\begin{array}{l}\text { TTG GTG AGG TCA GTG GTA } \\
\text { AGG A }\end{array}$ & & \\
\hline & $\begin{array}{l}\text { 2D6-SF11 } \\
\text { (2735 to 2756) }\end{array}$ & $\begin{array}{l}\text { 2850C }>T, 2935 A>C, \\
\text { 2950G }>C, 2988 G>A, \\
\text { 3183G }>A, 3201 C>T, \\
\text { 3259_3260insGT }\end{array}$ & $\begin{array}{l}\text { TGA CAG GTG CAG AAT } \\
\text { TGG AGG T }\end{array}$ & & \\
\hline & $\begin{array}{l}\text { 2D6-Ex9F2s } \\
\text { (3920 to 3938) }\end{array}$ & $\begin{array}{l}\text { 4125_4133insGTGCCCACT, } \\
4180 \mathrm{G}>\mathrm{C}\end{array}$ & $\begin{array}{l}\text { CCTTCC TGC CTTTCT } \\
\text { CAG C }\end{array}$ & & \\
\hline \multirow[t]{2}{*}{ 2D6 duplication detection } & 2D6dup sense & Gene duplication & $\begin{array}{l}\text { CCT GGG AAG GCC CCA } \\
\text { TGG AAG }\end{array}$ & \multirow{2}{*}{$\begin{array}{l}95^{\circ} \mathrm{C} 2 \mathrm{~min} ; 95^{\circ} \mathrm{C} 20 \mathrm{~s} \\
68^{\circ} \mathrm{C} 20 \mathrm{~s}, 72^{\circ} \mathrm{C} 2 \mathrm{~min}, \\
40 \text { cycles }\end{array}$} & \multirow[t]{2}{*}{ [33] } \\
\hline & 2D6dup antisense & Gene duplication & $\begin{array}{l}\text { CAG TTA CGG CAG TGG } \\
\text { TCA GCT }\end{array}$ & & \\
\hline \multirow[t]{2}{*}{$\begin{array}{l}\text { 2D6 deletion detection } \\
\text { Round } 1\end{array}$} & 2D6del01 sense & Gene deletion & $\begin{array}{l}\text { GTT GGA GCT CCT GAC } \\
\text { CTC TTC }\end{array}$ & \multirow{2}{*}{$\begin{array}{l}95^{\circ} \mathrm{C} 2 \mathrm{~min} ; 95^{\circ} \mathrm{C} 20 \mathrm{~s}, \\
60^{\circ} \mathrm{C} 20 \mathrm{~s}, 72^{\circ} \mathrm{C} 2 \mathrm{~min}, \\
50 \text { cycles }\end{array}$} & \multirow[t]{2}{*}{ This study } \\
\hline & 2D6del antisense & Gene deletion & $\begin{array}{l}\text { TAT ATG CCA GGG CTA } \\
\text { CCT CCC }\end{array}$ & & \\
\hline \multirow[t]{2}{*}{$\begin{array}{l}\text { 2D6 deletion detection } \\
\text { Round } 2\end{array}$} & 2D6del sense & Gene deletion & $\begin{array}{l}\text { ACC GGG CAC CTG TAC } \\
\text { TCC TCA }\end{array}$ & \multirow{2}{*}{$\begin{array}{l}95^{\circ} \mathrm{C} 2 \mathrm{~min} ; 95^{\circ} \mathrm{C} 20 \mathrm{~s}, \\
68^{\circ} \mathrm{C} 20 \mathrm{~s}, 72^{\circ} \mathrm{C} 2 \mathrm{~min} \\
40 \text { cycles }\end{array}$} & \multirow[t]{2}{*}{ [33] } \\
\hline & 2D6del antisense & Gene deletion & $\begin{array}{l}\text { GCA TGA GCT AAG GCA } \\
\text { CCC AGA C }\end{array}$ & & \\
\hline
\end{tabular}

test (Linear-by-Linear Association) was also used to compare AS distribution between ADF-R sub-groups with 1 relapse to sub-group with $\geq 2$ relapses. These analyses were performed using GraphPad Prism (version 6.05) and SPSS (V25).

\section{Human ethics}

The retrospective analysis of archived and de-identified samples was approved by Australian Defence Human
Research Ethics Committee (ADHREC 288-02 and 802-15).

\section{Results}

CYP2D6 alleles and allele frequency

A total of 16 CYP2D6 alleles were observed amongst the 157 ADF samples examined: 10 alleles were observed in the ADF-NR group and 15 in the ADF-R group. Allele type and frequency is shown in Fig. 1 and Table 2. Major alleles that each accounted for $>5 \%$ of the ADF-NR group 


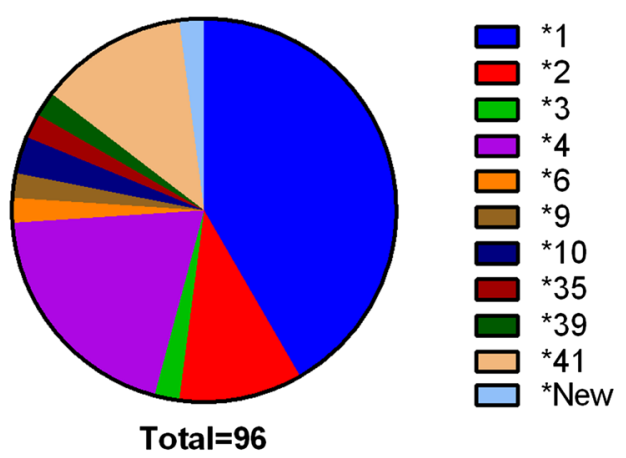

ADF-NR
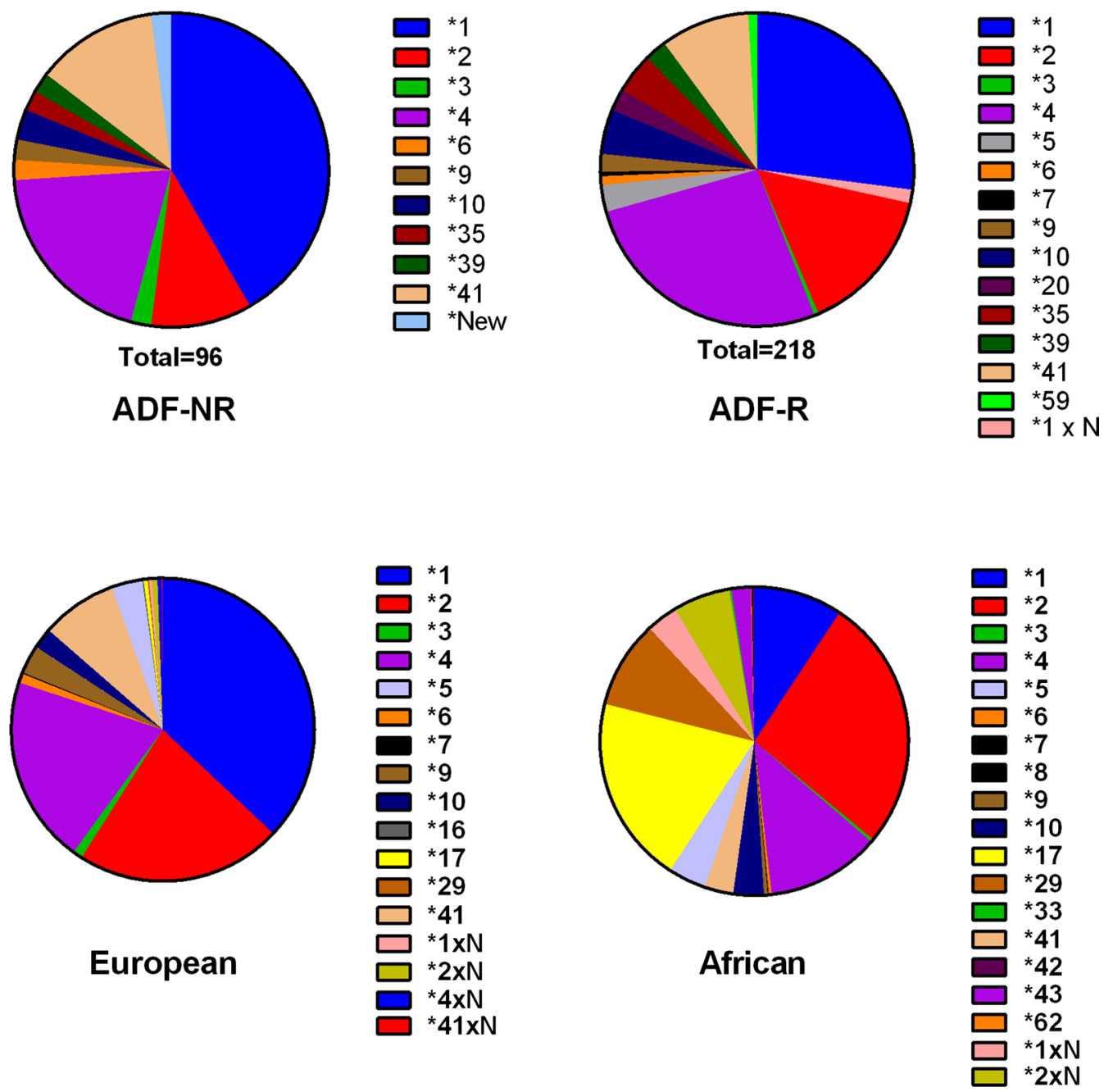

Fig. 1 CYP2D6 allele type and their frequency in ADF personnel (ADF-NR and ADF-R) and reference populations (European and African population)

were *1 (41.7\%), *4 (19.8\%), *41 (12.5\%), and *2 (10.4\%). These same major alleles were present in the ADF-R group: *1 (27.1\%), *4 (26.6\%), ${ }^{*} 2$ (15.1) and *41 (9.2\%). A single sample from the ADF-NR group had a deletion spaning from 1023 to $1863 \mathrm{bp}$ in the sequence, for which allelic type has not previously been defined in the existing database and was classified as a new allelic type.

Comparisons of allele frequency for major alleles (>5\%) between the two ADF groups (NR and R) and an European population [21] revealed that allelic profile of the ADF-NR group was not statistically different to the European population $(\mathrm{p}=0.054)$, while the ADF-R group had a significant higher proportion of * 4 and lower proportions of *1 and *2 than the European population ( $<<0.001$, Fig. 1). CYP2D6 allele frequency of an African population is included in Fig. 1 for illustration of a difference in allele frequency between populations. Both ADF groups differed significantly in allele frequency from the
African population $(\mathrm{p}<0.001)$. There was a significantly higher proportion of * 4 and lower proportion of * 1 in the ADF-R group compared to the ADF-NR group ( $\mathrm{p}<0.001$, Fig. 1).

After translating the observed CYP2D6 alleles to functionality (Table 2), there was a significant difference in the ADF-R group compared to both the European $(\mathrm{p}<0.007)$ and the ADF-NR $(\mathrm{p}=0.008)$ groups with increased proportion of NF and decreased proportion of FF/IF alleles in the ADF- $R$ group. There was no significant difference in proportion of functionality classification of the CYP2D6 alleles observed in the ADF-NR group compared to the European population $(\mathrm{p}=0.46)$.

\section{CYP2D6 allele diplotypes}

Homozygous CYP2D6 diplotypes were observed in 33/48 $(68.8 \%)$ and 39/109 (35.8\%) of the ADF-NR and ADF-R groups, respectively. When functionality classification of 
Table 2 Functionality of CYP2D6 alleles observed in ADF samples

\begin{tabular}{|c|c|c|c|c|c|c|}
\hline \multirow[t]{2}{*}{ Functionality } & \multirow[t]{2}{*}{ Allele } & \multicolumn{2}{|c|}{ ADF-NR } & \multicolumn{2}{|c|}{ ADF-R } & \multirow{2}{*}{$\begin{array}{l}\text { European [21] } \\
\%\end{array}$} \\
\hline & & No. & $\%$ & No. & $\%$ & \\
\hline Increased function (IF) & ${ }^{*} 1 \times N$ & 0 & 0.0 & 3 & 1.4 & 0.3 \\
\hline \multirow[t]{4}{*}{ Fully function (FF) } & $* 1$ & 40 & 41.7 & 59 & 27.1 & 37.0 \\
\hline & $*^{2} 2$ & 10 & 10.4 & 33 & 15.1 & 22.0 \\
\hline & *35 & 2 & 2.1 & 9 & 4.1 & 0.0 \\
\hline & *39 & 2 & 2.1 & 5 & 2.3 & 0.0 \\
\hline \multirow[t]{4}{*}{ Reduced function (RF) } & *9 & 2 & 2.1 & 4 & 1.8 & 3.0 \\
\hline & $* 10$ & 3 & 3.1 & 10 & 4.6 & 2.2 \\
\hline & $* 41$ & 12 & 12.5 & 20 & 9.2 & 8.1 \\
\hline & $* 59$ & 0 & 0.0 & 2 & 0.9 & 0.0 \\
\hline \multirow[t]{6}{*}{ Non-function (NF) } & *3 & 2 & 2.1 & 1 & 0.5 & 1.0 \\
\hline & *4 & 19 & 19.8 & 58 & 26.6 & 20.0 \\
\hline & $* 5$ & 0 & 0.0 & 6 & 2.8 & 3.3 \\
\hline & *6 & 2 & 2.1 & 2 & 0.9 & 1.0 \\
\hline & $* 7$ & 0 & 0.0 & 1 & 0.5 & 0.1 \\
\hline & *20 & 0 & 0.0 & 5 & 2.3 & 0.0 \\
\hline Unknown function & *New type & 2 & 2.1 & 0 & 0.0 & 0.0 \\
\hline Total & 16 & 96 & & 218 & & \\
\hline
\end{tabular}

Major alleles are shown in italics. Minor alleles in the European population that were not detected in the ADF groups are not shown in the table

Table 3 Number and proportion of CYP2D6 functionality diplotypes in ADF-NR and ADF-R group

\begin{tabular}{|c|c|c|c|c|c|c|c|c|c|c|}
\hline \multirow[t]{2}{*}{ Group } & \multirow[t]{2}{*}{ No } & \multicolumn{9}{|c|}{ Allele functionality combinations } \\
\hline & & IF/IF & IF/NF & $\mathrm{FF} / \mathrm{FF}$ & $\mathrm{FF} / \mathrm{RF}$ & $\mathrm{FF} / \mathrm{NF}$ & $\mathrm{RF} / \mathrm{RF}$ & NF/NF & RF/NF & New/new \\
\hline ADF-NR & 48 & 0 & 0 & 19 (39.6\%) & $9(18.8 \%)$ & $5(10.4 \%)$ & $4(8.3 \%)$ & $10(20.8 \%)$ & $0(0.0 \%)$ & $1(2.1 \%)$ \\
\hline ADF-R & 109 & $1(0.9 \%)$ & $1(0.9 \%)$ & $32(29.4 \%)$ & $17(15.6 \%)$ & $24(22.0 \%)$ & $6(5.5 \%)$ & $21(19.3 \%)$ & $7(6.4 \%)$ & $0(0.0 \%)$ \\
\hline Total & 157 & & & 54 & 26 & 28 & 11 & 31 & 6 & 1 \\
\hline
\end{tabular}

Diplotypes with significant difference between ADF-NR and ADF-R is indicated in italics

the diplotypes were analysed, there was a significant difference between the ADF-NR and ADF-R groups with the ADF-R having a higher proportion of FF/NF and $\mathrm{RF} / \mathrm{NF}(\mathrm{p}<0.001)$ (Table 3). The proportion of diplotypes with at least one IF or FF allele was $68.8 \%(33 / 48)$ and $68.8 \%(75 / 109)$ in the ADF-NR and ADF-R group, respectively. Importantly, individuals having NF/NF diplotypes accounted for approximately $20 \%$ in each of the ADF groups. $6.4 \%$ of individuals in the ADF-R group had a RF/NF diplotype.

\section{Predicted CYP2D6 phenotypes and activity score (AS)}

The distribution of predicted CYP2D6 phenotypes between the ADF-NR and ADF-R groups is shown in Fig. 2a. There was no significant difference between the two groups $(p=0.39)$. A generalized linear model revealed that CYP2D6 phenotype does not significantly influence whether relapse occurred.
Figure 2b shows the distribution of predicted CYP2D6 AS for each ADF group. Although the proportion of samples with $A S \geq 2$ was larger in the ADF-NR group than in the ADF-R group (39.6\% vs. $31.2 \%$ ), the proportion with $\mathrm{AS}=0$ was similar between the two groups $(20.8 \%$ vs. $19.3 \%$ for ADF-NR and ADF-R, respectively). When AS was grouped as $\mathrm{AS}<1.5$ and $\mathrm{AS} \geq 1.5$ there was no significant association with ADF groups $(p=0.165)$. The ROC analysis found that the AS score was not able to significantly discriminate between the two ADF groups $(\mathrm{p}=0.30)$.

\section{CYP2D6 profile in the ADF-R group with single} and multiple relapses

Within the ADF-R group, CYP2D6 allele profile was similar between personnel who experienced 1,2 and $3+$ relapses $(p=0.71$, Fig. 3a). There was no significant difference in the phenotypes between those who experienced one relapse compared to two or more relapses 
a

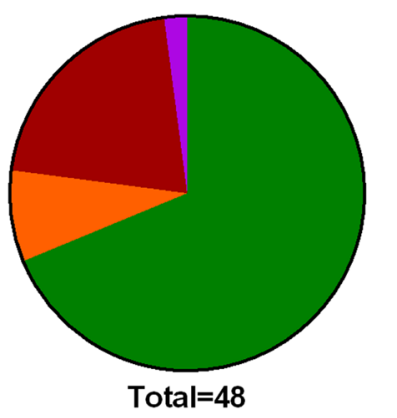

b

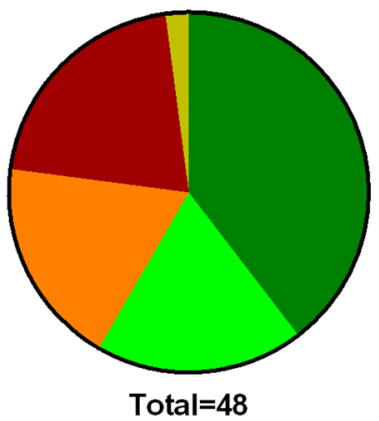

ADF-NR
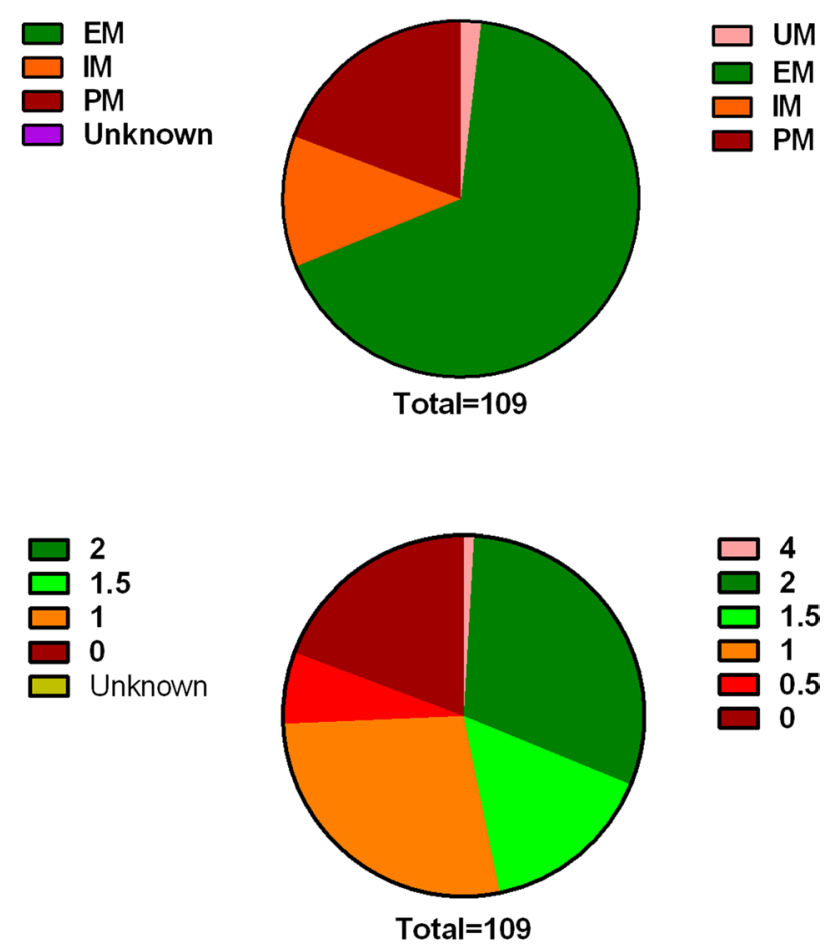

ADF-R

Fig. 2 Distribution of predicted CYP2D6 phenotypes (a) and activity scores (b) in ADF- NR and ADF-R groups

$(\mathrm{p}=0.477$, Fig. $3 \mathrm{~b})$, and no significant difference in the AS $(\mathrm{p}=0.40$, Fig. 3c).

\section{Discussion}

Malaria, especially relapsing vivax malaria remains a serious problem for people visiting malarious areas, particularly military populations including the ADF. PART is commonly used as an intervention measure to reduce the incidence of vivax relapses after leaving endemic countries and after relapse. The recommended dose of primaquine used in PART for the ADF was $22.5 \mathrm{mg}$ daily for 14 days (before April 2000) and $30 \mathrm{mg}$ daily for 14 days after April 2000 [15]. However, despite using PART relapsing vivax malaria in returning personnel is common. Within ADF personnel the median period between departing the endemic countries (PNG, East Timor and Solomon Islands) and having a primary presentation of $P$. vivax malaria was 86 days (range 1-505 days) [15]. Almost all cases were considered relapses resulted from hypnozoite activation since most personnel had their primary infection 3 weeks and after their return without further visits to endemic areas.

The aim of this study was to determine the CYP2D6 profile in a subset of ADF personnel deployed to PNG and East Timor and to explore whether their CYP2D6 activity can explain PART failure causing relapsing vivax malaria. Serum and blood samples from personnel deployed to PNG and East Timor were pooled for analysis for the following reasons: (1) both deployments took place within a short time frame (between 1999 and 2000) and a major change in ethnic composition of the troops during this period was unlikely; (2) all personnel received PART; (3) the malaria attack rate for ADF personnel deployed to these two countries were estimated to be similar at 1.1\% (52/4776) in PNG and 0.9\% (369/40571) in East Timor [15]; and (4) there were insufficient samples from each location to allow for statistically valid country-specific comparisons.

CYP2D6 alleles were determined by DNA sequencing and by PCR detection for copy number variations. The allele frequency determined for the ADF-NR group matched that of the European population, with the same major alleles. While the same four major alleles were also dominant in the ADF-R group, there was a significant increase in the proportion of non-function alleles (*4) and a decrease in proportion of functional alleles ("1), compared to the European population and the ADF-NR group. However, the difference disappeared when allelic types were interpreted into phenotype and ASs. The proportion of diplotypes with at least one functional allele 


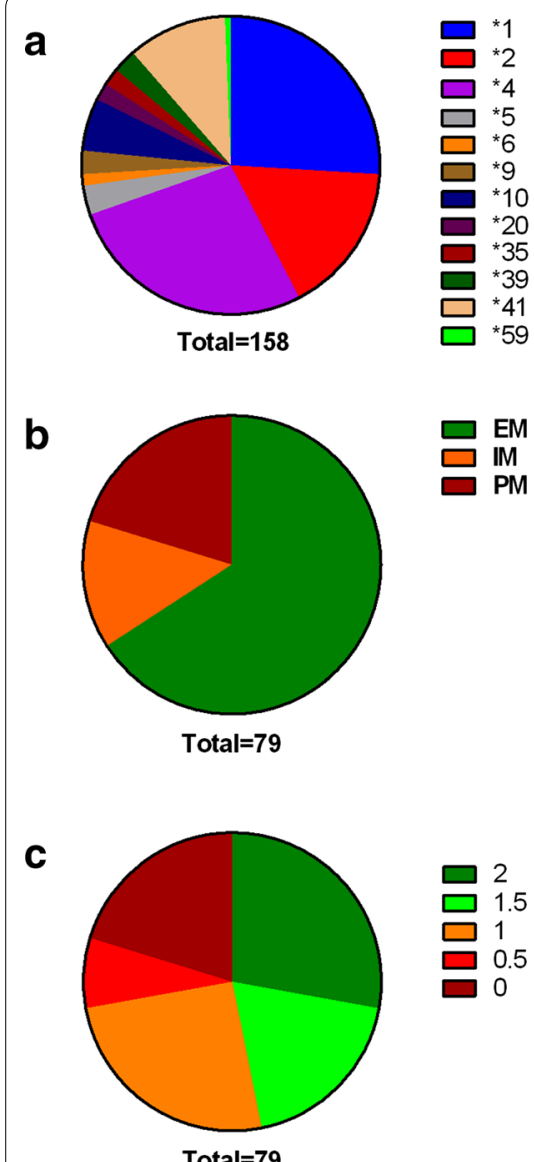

ADF-R (1 Relapse)
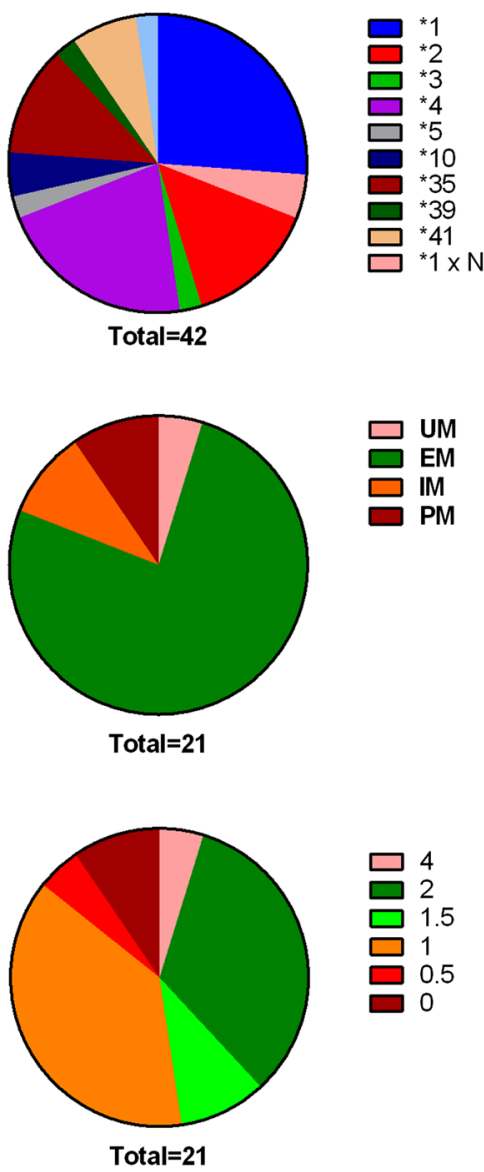

ADF-R (2 Relapses)
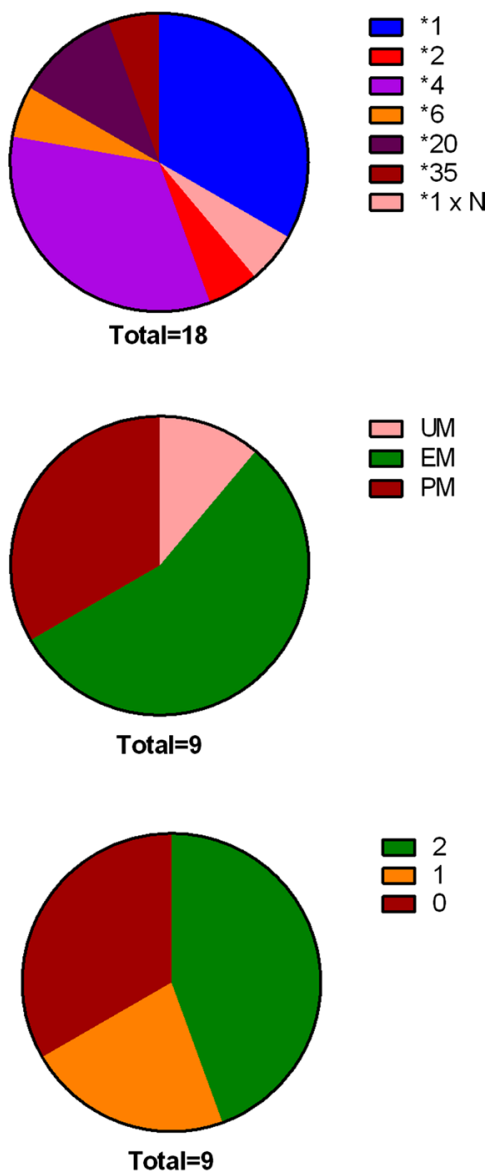

ADF-R (>3 Relapses) $\mathrm{n}=\mathbf{9}$

Fig. 3 Comparison of CYP2D6 profile within the ADF-R group: $\mathbf{a}$ allele frequency; $\mathbf{b}$ predicted phenotype; $\mathbf{c}$ activity score

was identical between the two ADF groups at $68.8 \%$. This provides an explanation for why difference in allelic frequency was not translated into difference in phenotype frequency.

Comparable phenotype and ASs were observed between the ADF-R and ADF-NR groups suggesting that CYP2D6 was not the determining factor of whether a relapse occurred or not after PART. Other factors could contribute to relapsing vivax malaria in this cohort including poor adherence to the 14 day PART regimens and tolerance of $P$. vivax to primaquine. For the latter, $P$. vivax strains in Oceania are considered tolerant to primaquine [13]. The majority of ADF personnel returned before April 2000 and were prescribed primaquine at $22.5 \mathrm{mg}$ daily for 14 days, which is equivalent to $0.32 \mathrm{mg} / \mathrm{kg}$ based on a body weight for a $70 \mathrm{~kg}$ individual. Although not weight adjusted this dose is within the WHO recommended dose range for primaquine
(0.25-0.5 $\mathrm{mg} / \mathrm{kg}$ daily for 14 days). However, the dose may not be sufficient to kill all hypnozoites in the liver. The current recommended primaquine dose for the ADF is $30 \mathrm{mg}$ daily for 14 days.

A limitation of the study was that administration of primaquine was not directly observed as the PART regime is routinely prescribed for returning ADF personnel. Findings from field trials have shown significantly higher recurrence of $P$. vivax infections in unobserved primaquine treatment arms compared to directly observed primaquine treatment $[9,11]$.

In this study, the investigation into the CYP2D6 status of the ADF personnel in the development of vivax relapses is further complicated because not all personnel in the deployment would be expected to have been bitten by $P$. vivax-infected mosquitoes. While over 400 relapsing $P$. vivax infections reported in the returning personnel suggesting a moderate exposure to $P$. vivax infections 
[15], there is no guarantee that every individual had exposures during deployment and currently there is no validated marker to quantify exposure. If an individual has not been exposed to $P$. vivax then PART failure would not occur, irrespective of their CYP2D6 status. Therefore, the definitive analysis of the role of CYP2D6 status in the success/failure of PART requires that all individuals are at least exposed to vivax malaria. However, it is not possible to conduct such a study since a key objective during deployment (and travel in general) is to prevent exposure to infected mosquitoes through the use of insecticides, bed nets, repellents and insecticide-impregnated clothing. Future prospective studies should minimize the effect of these confounders.

In order to reduce the potential confounder effect of exposure to infection and adherence to PART, CYP2D6 profile within the ADF-R group was compared between sub-groups who experienced 1, 2 or more relapses. These personnel have all suffered from at least one relapse of the debilitating $P$. vivax infection after their return to Australia and therefore had good incentives to avoid experiencing further relapses, and thus are more likely to adhere to the full course of PART. However, no correlation between CYP2D6 alleles and additional relapses were obtained although there were trends suggesting an association between low AS (0-1) and experiencing multiple relapses. The results indicate that primaquine tolerance may be the major contributing factor to relapses and the higher dose regimen of primaquine $(0.5 \mathrm{mg} / \mathrm{kg}$ per day for 14 days) should be used for PART.

Although the outcome of this study suggests that the CYP2D6 status in ADF personnel was not the determining factor for relapsing vivax malaria, it does not rule out that CYP2D6 status will affect efficacy of PART in future military operations, especially in individuals having a CYP2D6 diplotype with both non-function alleles. This cohort made up $20 \%$ of the current study. Importantly, the study highlights the importance of ensuring adequate primaquine dosing and adherence to PART to reduce the risk of relapsing $P$. vivax. This applies to both military and civilian populations.

\section{Conclusions}

CYP2D6 status was not the dominant factor for PART failure causing relapsing vivax malaria in a cohort of ADF personnel returning from deployment in PNG and East Timor between 1999 and 2001. Other factors such as adherence to PART and primaquine tolerate P. vivax are likely contributors to relapses. The results highlight the importance of ensuring adequate primaquine dosing and adherence for preventing relapsing vivax malaria.

\section{Abbreviations}

CYP2D6: cytochrome P450 2D6; PART: primaquine anti-relapse therapies; ADF: Australian Defence Force; ADFMIDI: Australian Defence Force Malaria and Infectious Disease Institute; PNG: Papua New Guinea; ADF-NR: ADF no $P$. vivax relapse; ADF-R: ADF had P. vivax relapse; RDTs: rapid diagnostic tests; G6PD: glucose-6-phosphate dehydrogenase; UM: ultrarapid metabolizer; EM: extensive metabolizer; IM: intermediate metabolizer; PM: poor metabolizer; IF allele: increased funtion allele; FF allele: fully function allele; RF allele: reduced function allele; NF allele: non-function allele; AS: activity score; ROC analysis: receiver operating characteristic curve analysis.

\section{Authors' contributions}

AA, MDE, SD collected samples; NC, SD processed samples and performed molecular determination of CYP 2D6 allelic types and predicted phenotype; MLG performed statistical analyses; NC, QC, MLG analysed data; AA, MDE and QC conceived the study; NC, MLG, MDE and QC prepared the manuscript. All authors read and approved the final manuscript.

\section{Author details}

${ }^{1}$ Australian Defence Force Malaria and Infectious Disease Institute, Brisbane, QLD, Australia. ${ }^{2}$ School of Public Health and Social Work, Queensland University of Technology, Brisbane, QLD, Australia.

\section{Acknowledgements}

The authors would like to thank Prof. Dennis Shanks for constructive discussions.

\section{Competing interests}

The authors declare that they have no competing interests.

\section{Authors' declaration}

The opinions expressed herein are those of the authors only and do not necessarily reflect those of the Australian Defence Force Joint Health Command.

Availability of data and materials

Not applicable.

Consent for publication

Not applicable.

\section{Ethics approval and consent to participate}

The retrospective analysis of archived and de-identified samples was approved by Australian Defence Human Research Ethics Committee (ADHREC 288-02 and 802-15).

\section{Funding}

The project was funded by Australian Defence Organization. MLG is supported by School of Public Health and Social Work, Queensland University of Technology.

\section{Publisher's Note}

Springer Nature remains neutral with regard to jurisdictional claims in published maps and institutional affiliations.

Received: 16 January 2019 Accepted: 11 April 2019

Published online: 18 April 2019

References

1. WHO. World malaria report 2017. Geneva: World Health Organization. 2017. http://www.who.int/malaria.

2. Howes RE, Battle KE, Mendis KN, Smith DL, Cibulskis RE, Baird JK, et al. Global epidemiology of Plasmodium vivax. Am J Trop Med Hyg. 2016;95:15-34

3. Cheng Q, Cunningham J, Gatton ML. Systematic review of sub-microscopic P. vivax infections: prevalence and determining factors. PLoS Negl Trop Dis. 2015;9:e3413.

4. Robinson L, Wampfler R, Betuela I, Karl S, White MT, Li W, Suen CS, et al. Strategies for understanding and reducing the Plasmodium vivax and 
Plasmodium ovale hypnozoite reservoir in Papua New Guinean children: a randomised placebo-controlled trial and mathematical model. PLoS Med. 2015;12:e1001891.

5. Recht J, Siqueira AM, Monteiro WM, Herrera SM, Herrera S, Lacerda MVG. Malaria in Brazil, Colombia, Peru and Venezuela: current challenges in malaria control and elimination. Malar J. 2017;16:273.

6. Oloifana-Polosovai H, Gwala J, Harrington H, Massey PD, Ribeyro E, Flores $A$, et al. A marked decline in the incidence of malaria in a remote region of Malaita, Solomon Islands, 2008 to 2013. Western Pac Surveill Response J. 2014;5:30-9.

7. Maude RJ, Nguon C, Ly P, Bunkea T, Ngor P, Canavati de la Torre SE, et al. Spatial and temporal epidemiology of clinical malaria in Cambodia 2004-2013. Malar J. 2014;13:385.

8. WHO. Guidelines for the treatment of malaria. 3rd ed. Geneva: World Health Organization; 2015. http://www.who.int/malaria/publications/ atoz/9789241549127/en.

9. Takeuchi R, Lawpoolsri S, Imwong M, Kobayashi J, Kaewkungwal J, Pukrittayakamee S, et al. Directly-observed therapy (DOT) for the radical 14-day primaquine treatment of Plasmodium vivax malaria on the Thai-Myanmar border. Malar J. 2010:9:308.

10. Khantikul N, Butraporn P, Kim HS, Leemingsawat S, Tempongko MA, Suwonkerd W. Adherence to antimalarial drug therapy among vivax malaria patients in northern Thailand. J Health Popul Nutr. 2009;27:4-13.

11. Maneeboonyang W, Lawpoolsri S, Puangsa-Art S, Yimsamran S, Thanyavanich $\mathrm{N}$, Wuthisen $\mathrm{P}$, et al. Directly observed therapy with primaquine to reduce the recurrence rate of Plasmodium vivax infection along the Thai-Myanmar border. Southeast Asian J Trop Med Public Health. 2011;42:9-18.

12. Abreha T, Hwang J, Thriemer K, Tadesse Y, Girma S, Melaku Z, et al. Comparison of artemether-lumefantrine and chloroquine with and without primaquine for the treatment of Plasmodium vivax infection in Ethiopia: a randomized controlled trial. PLoS Med. 2017;14:e1002299.

13. Collins WE, Jeffery GM. Primaquine resistance in Plasmodium vivax. Am J Trop Med Hyg. 1996;55:243-9.

14. Ho W. Guidelines for the treatment of malaria. Geneva: World Health Organization; 2006

15. Elmes NJ. Malaria notifications in the Australian Defence Force from 1998 to 2007. Int Health. 2010;2:130-5.

16. John GK, Douglas NM, von Seidlein L, Nosten F, Baird JK, White NJ, et al. Primaquine radical cure of Plasmodium vivax: a critical review of the literature. Malar J. 2012;11:280.

17. Pybus BS, Sousa JC, Jin X, Ferguson JA, Christian RE, Barnhart R, et al. CYP450 phenotyping and accurate mass identification of metabolites of the 8-aminoquinoline, anti-malarial drug primaquine. Malar J. 2012;11:259.

18. Pybus BS, Marcsisin SR, Jin X, Deye G, Sousa JC, Li Q, et al. The metabolism of primaquine to its active metabolite is dependent on CYP 2D6. Malar J. 2013;12:212.

19. Sistonen J, Sajantila A, Lao O, Corander J, Barbujani G, Fuselli S. CYP2D6 worldwide genetic variation shows high frequency of altered activity variants and no continental structure. Pharmacogenet Genomics. 2007:17:93-101.

20. Gaedigk A, Simon SD, Pearce RE, Bradford LD, Kennedy MJ, Leeder JS. The CYP2D6 activity score: translating genotype information into a qualitative measure of phenotype. Clin Pharmacol Ther. 2008;83:234-42.
21. Zhou Y, Ingelman-Sundberg M, Lauschke VM. Worldwide distribution of cytochrome P450 alleles: a meta-analysis of population-scale sequencing projects. Clin Pharmacol Ther. 2017;102:688-700.

22. Bradford LD. CYP2D6 allele frequency in European Caucasians, Asians, Africans and their descendants. Pharmacogenomics. 2002;3:229-43.

23. Broly F, Gaedigk A, Heim M, Eichelbaum M, Morike K, Meyer UA. Debrisoquine/sparteine hydroxylation genotype and phenotype: analysis of common mutations and alleles of CYP2D6 in a European population. DNA Cell Biol. 1991:10:545-58.

24. Sachse C, Brockmoller J, Hildebrand M, Muller K, Roots I. Correctness of prediction of the CYP2D6 phenotype confirmed by genotyping 47 intermediate and poor metabolizers of debrisoquine. Pharmacogenetics. 1998:8:181-5.

25. Bennett JW, Pybus BS, Yadava A, Tosh D, Sousa JC, McCarthy WF, et al. Primaquine failure and cytochrome P-450 2D6 in Plasmodium vivax malaria. N Engl J Med. 2013;369:1381-2.

26. Ingram RJ, Crenna-Darusallam C, Soebianto S, Noviyanti R, Baird JK. The clinical and public health problem of relapse despite primaquine therapy: case review of repeated relapses of Plasmodium vivax acquired in Papua New Guinea. Malar J. 2014:13:488.

27. Brasil LW, Rodrigues-Soares F, Santoro AB, Almeida ACG, Kuhn A, Ramasawmy $R$, et al. CYP2D6 activity and the risk of recurrence of Plasmodium vivax malaria in the Brazilian Amazon: a prospective cohort study. Malar J. 2018;17:57.

28. Silvino AC, Costa GL, Araujo FC, Ascher DB, Pires DE, Fontes CJ, et al. Variation in human cytochrome P-450 drug-metabolism genes: a gateway to the understanding of Plasmodium vivax relapses. PLoS ONE. 2016;11:e0160172.

29. Baird JK, Louisa M, Noviyanti R, Ekawati L, Elyazar I, Subekti D, et al. Association of impaired cytochrome P450 2D6 activity genotype and phenotype with therapeutic efficacy of primaquine treatment for latent Plasmodium vivax malaria. JAMA Network Open. 2018;1:e181449.

30. Bright AT, Alenazi T, Shokoples S, Tarning J, Paganotti GM, White NJ, et al. Genetic analysis of primaquine tolerance in a patient with relapsing vivax malaria. Emerg Infect Dis. 2013;19:802-5.

31. Edstein MD, Walsh DS, Eamsila C, Sasiprapha T, Nasveld PE, Kitchener S, et al. Malaria prophylaxis/radical cure: recent experiences of the Australian Defence Force. Med Trop (Mars). 2001;61:56-8.

32. Chen N, Auliff A, Rieckmann K, Gatton M, Cheng Q. Relapses of Plasmodium vivax infection result from clonal hypnozoites activated at predetermined intervals. J Infect Dis. 2007;195:934-41.

33. Gaedigk A, Sangkuhl K, Whirl-Carrillo M, Klein T, Leeder JS. Prediction of CYP2D6 phenotype from genotype across world populations. Genet Med. 2017;19:69-76.

34. Fang H, Liu X, Ramirez J, Choudhury N, Kubo M, Im HK, et al. Establishment of CYP2D6 reference samples by multiple validated genotyping platforms. Pharmacogenomics J. 2014;14:564-72.

35. Gressier F, Verstuyft C, Hardy P, Becquemont L, Corruble E. Response to CYP2D6 substrate antidepressants is predicted by a CYP2D6 composite phenotype based on genotype and comedications with CYP2D6 inhibitors. J Neural Transm (Vienna). 2015;122:35-42.

Ready to submit your research? Choose BMC and benefit from

- fast, convenient online submission

- thorough peer review by experienced researchers in your field

- rapid publication on acceptance

- support for research data, including large and complex data types

- gold Open Access which fosters wider collaboration and increased citations

- maximum visibility for your research: over $100 \mathrm{M}$ website views per year

At BMC, research is always in progress.

Learn more biomedcentral.com/submissions 